\title{
ONDE A COMIDA NÃO TEM GOSTO: UMA ANÁLISE DO GOSTO COMO PRÁTICA E INTERAÇÃO
}

\author{
WHERE FOOD HAS NO TASTE: \\ ANALYSIS OF TASTE AS PRACTICE AND INTERACTION
}

Viviane Kraieski de Assunção*

\section{Introdução}

A fim de problematizar as mudanças e continuidades das práticas alimentares, realizei uma pesquisa etnográfıca com imigrantes brasileiros na Grande Boston, Estado de Massachusetts, nos Estados Unidos. Meu objetivo era questionar uma afırmação muito recorrente em estudos da área da Antropologia e da Sociologia da Alimentação: a fixidez das práticas alimentares, entendida como um dos aspectos socioculturais mais resistentes a mudanças, e um dos últimos a se "desnacionalizar".

Os sujeitos de minha pesquisa não tinham grandes dificuldades em encontrar e preparar "comida brasileira" na Grande
Boston. 0 grande número de restaurantes, mercados e padarias ${ }^{1}$, além da oferta de alimentos brasileiros em supermercados norte-americanos, possibilita o que pode ser compreendido, por meio dos discursos de meus interlocutores, como uma manutenção das práticas alimentares que tinham no Brasil. Quando perguntados sobre o que comiam em Boston, eles eram unânimes em responder que era "comida brasileira". A resposta sobre o que é essa "comida brasileira” não é, porém, homogênea, dada a grande heterogeneidade de meus sujeitos de pesquisa, de suas origens (são provenientes de diferentes estados brasileiros e classes sociais) e trajetórias de vida. A “comida brasileira”, portanto, pode compreen-

*Professora do Programa de Pós-Graduação em Ciências Ambientais (PPGCA) da Universidade do Extremo Sul Catarinense (UNESC/Criciúma/SC/Brasil). É doutora e mestre em Antropologia Social (PPGAS/UFSC), e realizou pós-doutorado em Antropologia Social e Cultural na Vrije Universiteit Amsterdam. vivianekraieski@gmail.com. 1. Não há levantamentos com dados precisos, mas estima-se que haja mais de mil negócios em Massachusetts cujos donos são brasileiros, incluindo pequenos mercados, açougues, padarias, restaurantes, entre outros estabelecimentos (MENDONÇA, 2007). 
der tanto o arroz e feijão, consumido por um grande número de brasileiros (BARBOSA, 2007), como também macarrão, carnes assadas e ensopadas, e ainda pratos marcados por sua regionalidade, como feijão tropeiro e frango com quiabo.

Apesar da oferta de "comida brasileira”, a afırmação de meus interlocutores de que a comida em Boston "não tem gosto" era constante. Era classificada pelos sujeitos de pesquisa como "sem gosto" uma grande variedade de alimentos: frutas, verduras, legumes, carnes, comidas prontas em restaurantes norte-americanos e até mesmo produtos industrializados brasileiros, como o café e a cerveja. Segundo meus interlocutores, a comida de lá não tem gosto ou sabor como a do Brasil. Nos anúncios de restaurantes, é evidente esta associação entre Brasil e gosto ou sabor. Muitos dos estabelecimentos apresentam o slogan "gostinho do Brasil", o que remete a algo mais do que o sabor, pois se relaciona à incorporação de uma nostalgia do país por meio dos alimentos.

Afirmar que as comidas na sociedade de destino não têm gosto não é exclusividade dos imigrantes brasileiros em Boston. A depreciação da comida do "outro" ou de "outros" lugares parece se estender a diferentes populações migrantes em diversos tempos e espaços. É bastante comum que o gosto seja apresentado como algo que algumas comidas apresentam, enquanto outras não, e que esteja associado às comidas das localidades de origem dos imigrantes. No entanto, proponho aqui entender o gosto e a falta de gosto, que tão recorrentemente aparecem nos discursos dos indivíduos que migram, a partir de meus interlocutores, sem a pretensão de generalizar sua experiência à de outros grupos migrantes.
Além dessa afırmação recorrente de que a comida não tinha gosto, entrevistando brasileiros também ouvi com frequência que era possível "se acostumar" ao gosto da comida preparada lá. "A gente se acostuma”, disseram-me vários interlocutores. Deste modo, os sujeitos de minha pesquisa apresentavam a possibilidade de "aprender a gostar" de algo. Ainda que não fosse possível que a comida de lá tivesse o gosto do Brasil, era possível acostumar-se a ela e ao gosto dela.

Essas afırmações levaram-me a questionar o que é gosto e o processo de sua formação. Neste artigo, proponho-me a interpretar o gosto a partir de duas perspectivas teóricas distintas: como prática - o que confere ao gosto a dinamicidade das ações cotidianas; e como elemento constituinte das interações sociais - que posicionam o gosto nas estratégias diárias dos sujeitos da pesquisa para lidar com as dificuldades enfrentadas com a migração para outro país. Antes, porém, discorro acerca da literatura socioantropológica sobre alimentação e migração, que tensiona a relação entre mudanças e continuidades, e caracterizo os sujeitos de minha pesquisa.

\section{Universo da pesquisa: heterogeneidade dos brasileiros na Grande Boston}

Os Estados Unidos são o principal destino dos emigrantes brasileiros. Segundo o IBGE, que pesquisou pela primeira vez o número de emigrantes brasileiros no Censo de 2010, há 491.243 brasileiros residentes em 193 países do mundo, sendo que, deste total, 23,8\% vivem nos Estados Unidos. Estes números, no entanto, são controversos, já que há um grande contingente de indocumentados. Um estudo anterior estimou que, só nos Estados Unidos, haveria entre 
800 mil e 1,4 milhão de brasileiros, sendo que a maior concentração - 24\%, o que corresponde a 336.000 pessoas - estaria no Estado de Massachusetts (LIMA, 2009).

Durante minha pesquisa de campo, pude perceber a heterogeneidade dos brasileiros na Grande Boston. Ainda que possa ser verificado um grande número de mineiros, conheci brasileiros provenientes de diversos estados brasileiros. Eram de diferentes faixas etárias - variando de 22 a 65 anos -, e níveis educacionais - desde brasileiros com pouca educação formal até aqueles que concluíram o ensino superior. Tinham também diferentes tempos de permanência nos Estados Unidos e status migratório brasileiros indocumentados, com visto de estudante, Green Card (residente permanente legal) e até mesmo com dupla cidadania (brasileira e norte-americana) -, mas os que lá viviam ilegalmente e que tinham migrado após o ano 2000 eram visivelmente mais numerosos. Esses brasileiros tinham em comum o fato de terem ido para os Estados Unidos a partir do contato com e de informações de outros brasileiros, com quem tinham laços de parentesco ou de amizade, o que evidencia que fazem parte de redes sociais (BOYD, 1989; MASSEY, 1990).

Ainda que eu tenha encontrado brasileiros com diferentes motivações para migrar, a maioria tinha ido para os Estados Unidos com a intenção de passar um período de tempo (em torno de quatro anos) e retornar para o país após realizarem seu projeto migratório, como o de comprar uma casa própria, montar um negócio ou pagar os estudos dos filhos. Nesse sentido, concordo com Sayad (1998) sobre a dupla contradição que muitos emigrantes vivem: o estado provisório da emigração e o prolongamento da condição de emigrante por tempo indeterminado.

Todos os interlocutores da pesquisa trabalhavam em funções ocupadas por migrantes com pouca ou nenhuma qualificação profissional: serviços de limpeza de casa (como housecleaner e housekeeper) ${ }^{2}$, jardinagem (landscaping), delivery (trabalhos de entrega em domicílio, principalmente de comidas e jornais), trabalhos em cozinhas de restaurantes e na construção civil. Os imigrantes provenientes de camadas médias no Brasil experienciavam, nas funções ocupadas nos Estados Unidos, um movimento descendente de status, realizando trabalhos de pouco prestígio social. Como comentou uma de minhas interlocutoras, "aqui não vale o diploma nem o dinheiro", pois, segundo ela, o status social é definido pela situação migratória, já que os maiores privilégios - como a possibilidade de vir ao Brasil e voltar para o país -, são daqueles que vivem legalmente nos Estados Unidos.

Ainda que relatem um aumento nos ganhos financeiros nos Estados Unidos, esses imigrantes experienciam muitas dificuldades, especialmente os indocumentados: árdua rotina de trabalho, exploração dos empregadores, ameaças de deportação, pouco ou nenhum conhecimento da língua inglesa, falta de acesso ao sistema de saúde, além da saudade de familiares e amigos que permaneceram no Brasil.

Se antes os brasileiros nos Estados Unidos eram descritos como comunidade invisível (MARGOLIS, 1998), sua presença na Grande Boston pode ser percebida de diversas formas, como nos mercados étnicos, nas

2. Housecleaner pode ser traduzido como faxineira ou diarista, que realiza eventuais trabalhos de limpeza em casas. Já housekeeper pode ser traduzido como empregada doméstica, que trabalha diariamente em apenas uma casa ou para somente uma família. 
igrejas, nos jornais e nas rádios brasileiras, e em sua concentração em algumas cities e towns, como Everett, Sommerville, Allston e Framingham, alterando a sua paisagem (MARCUS, 2009). Como afirmei no início deste artigo, a oferta de produtos e serviços voltados a brasileiros possibilita que os imigrantes tenham práticas alimentares similares às que tinham antes de migrarem para os Estados Unidos. A seguir, recupero algumas discussões sobre a alimentação em contexto migratório, para questionar as mudanças e continuidades desse elemento tão essencial à manutenção da vida biológica e sociocultural.

\section{Comida e migração: entre mudanças e continuidades}

A literatura socioantropológica considera a alimentação um elemento privilegiado para o estudo da vida social por suas dimensões socioculturais. Esses estudos têm destacado que os seres humanos não se alimentam apenas de nutrientes, mas também de símbolos e representações que atribuem aos alimentos que consomem. A comida, como ensina Lévi-Strauss, não é boa para pensar porque é boa para comer, mas é boa para comer porque é boa para pensar: primeiramente os seres humanos classificam os alimentos, e depois os inserem ou não na ordem do comestível (LÉVI -STRAUSS, 1965). Além do ato alimentar, a etiqueta à mesa e os modos de preparo dos alimentos são também atos concretos que se constituem em lugares de leitura de valores e representações culturais (POULAIN, 2004). Comer é ainda uma atividade rotineira que assume uma posição central no aprendizado social, e pode ser reveladora da cultura em que cada um está inserido (MINTZ, 2001).
A literatura antropológica retrata as relações entre alimentação, cultura e sociedade, trazendo a alimentação como elemento de distintividades e semelhanças entre grupos sociais. Segundo Douglas, qualquer culinária está relacionada a uma visão de mundo, a uma cosmologia. 0 sistema culinário ordena o mundo de uma forma específica - identificar uma comida é identificar seu lugar específico, o que compreende distinguir e classificar os elementos nos quais consiste a alimentação (DOUGLAS, 1971). A comida marca tanto uma ação universal (LÉVI-STRAUSS, 1965) como define identidades e estilos de vida regionais e nacionais: "os alimentos que incorporamos nos incorporam por sua vez ao mundo, nos situam no universo" (FISCHLER, 1995, p. 375). A necessidade de comer está inserida em um sistema de valores próprio de cada cultura, como demonstra Lévi-Strauss ao fazer uma analogia entre o sistema culinário e a língua. Os vértices do "triângulo culinário" - o cru, o cozido e o apodrecido - são comparados aos fonemas $a, i, u$ ou $k$, $p, t$, falados em todas as línguas, tomando, porém, diferentes formas em cada uma delas (LÉVI-STRAUSS, 1965).

Grande ênfase nas pesquisas na área da Antropologia da Alimentação foi dada a questões sobre comida e identidade. Salientando essa relação, Maciel (2005) afırma que a construção da cozinha acompanha os processos de identificação a qualquer unidade de pertencimento - seja um país, uma região, um grupo étnico ou outro conjunto.

A alimentação, segundo diversos autores, pode expressar tanto identidades quanto diferenças culturais que são construídas nas experiências migratórias. Como afirmam Contreras e Gracia (2004), a comida é um elemento importante que serve para que os grupos tomem consciência de sua 
diferença e etnicidade - entendida pelos autores como um sentimento de fazerem parte de uma entidade cultural distinta - de forma que seu compartilhamento pode significar o reconhecimento e a aceitação ou a incorporação dessas diferenças.

Discutindo sobre as relações entre comida e identidades nacionais e étnicas, alguns autores argumentam que a continuidade de um sistema alimentar étnico depende do grau de segregação do grupo social tido como minoria no conjunto de uma sociedade mais ampla. 0 sociólogo norte-americano Herbert Gans (1962), estudando uma comunidade italiana nos Estados Unidos, observa que os itens da culinária italiana são muito mais valorizados em situações que contrariam as regras sociais do grupo, como o casamento de um de seus membros com um outsider. Já Peter Fry (1982) analisa por que a feijoada tornou-se símbolo de nacionalidade brasileira, diferentemente do que ocorreu nos Estados Unidos, onde é classificada como soul food - símbolo da negritude utilizado por movimentos negros. 0 autor inspira-se na teoria da poluição e sujeira de Mary Douglas, que diz que partes da sociedade e da natureza que são classificadas como estando fora da estrutura formal de poder são consideradas sujas e poluidoras, ao mesmo tempo que são dotadas de certos poderes e que representam perigos. 0 autor conclui que, quando símbolos de fronteiras étnicas são conver- tidos em símbolos que afirmam os limites da nacionalidade, converte-se o que era originalmente perigoso em algo "limpo", "seguro" e "domesticado", e, sobretudo, em algo destituído do poder que o constituía anteriormente. $^{3}$

Pioneiros nos estudos sobre alimentação no Brasil, Gilberto Freyre e Câmara Cascudo trataram a alimentação como elemento constitutivo da identidade nacional e das identidades regionais. Atuando principalmente na primeira metade do século $\mathrm{XX}$, os dois intelectuais buscaram valorizar elementos populares considerados pelas elites nacionais como "atrasados", destacando a especificidade do país como mestiço e miscigenado. Dessa forma, contribuíram para construir uma identidade nacional refutando os argumentos eugenistas que relacionavam a miscigenação com a degradação e o atraso cultural e social. Nesse contexto, a feijoada passou a ser destacada como um "prato típico da culinária brasileira". ${ }^{4}$

Originalmente conhecida como "comida de escravos", a feijoada se converte, a partir dos anos 1930, em “comida nacional”, carregando a representação simbólica da mestiçagem associada à ideia da nacionalidade (SCHWARCZ, 1995; REIS, 1994). Assim como a feijoada no Brasil, outras comidas são associadas a identidades nacionais, como aponta a revisão sobre estudos antropológicos de alimentação feita por Mintz (2001). Os donuts são apontados por Steven

3. Em artigo posterior, Fry revê algumas dessas conclusões. 0 autor afirmou ter sido influenciado pelo contexto intelectual da década de 1970, dominado pelo marxismo. Em relação à feijoada, ele mantém o argumento de que seria o exemplo da transformação de um símbolo étnico em símbolo nacional. Porém, concluiu, repensando suas afirmações anteriores, que isso não ocultou a dominação racial, pois nenhum elemento seria capaz de fazê-lo. Fry sustenta ainda que há, no Brasil, o ideal da mistura racial, o que dificulta o combate ao racismo e às hierarquias raciais (FRY, 2001).

4. Pesquisadores desenvolvem estudos de Cascudo e Freyre sobre as abordagens dos dois autores sobre comida e identidades nacional e regional. Ver, por exemplo, os trabalhos de Dutra (2005), Cavignac e Oliveira (2010) e Gonçalves (2004). 
Penfold (2008) como símbolos do patriotismo canadense e do anti-americanismo. 0 autor explora as condições sociais e políticas que levaram ao rápido crescimento das lojas de donuts no país, considerando as questões socioeconômicas e culturais mais amplas que contribuíram para a formação de uma sociedade de consumo. Já a sopa de massa pho bo, típica do Vietnã do Sul, tornou-se símbolo da identidade nacional vietnamita quando o Vietnã do Norte e do Sul se uniram, como mostra Thach Giao Truong (s/d apud MINTZ, 2001). A antropóloga mostra como as preferências alimentares revelam as distinções entre o norte e o sul, que também revelam diferenças políticas, culturais e econômicas. No México, a tortilla, como informa o estudo de Jeffrey Pilcher (1998), passou a ser símbolo identitário. 0 autor afirma que, no contexto de uma sociedade hierárquica, a tortilla ajudou a definir a etnicidade em um país que não tinha claras delimitações raciais. Ele explora a mistura entre gostos de elite e gostos populares na formação de um "nacionalismo popular revolucionário" 5 .

Por suas relações com a(s) identidade(s), a alimentação é recorrentemente apontada como um dos marcadores de distintividades entre grupos no contexto da migração, tornando visível o processo de construção de fronteiras étnicas. Algumas comidas, assim como outros elementos culturais, são etnizadas, e servem como elementos a partir dos quais os migrantes passam a se identificar (e ser identificados) como grupo étnico. Estudos antropológicos destacam a manu- tenção de práticas alimentares dos migrantes nos países para onde migraram. Lesdain (2002) afirma que os hábitos alimentares são os que melhor resistem às mudanças por serem culturalmente e biologicamente interiorizados. Por isso, seriam indicadores do grau de integração dos migrantes.

Devido a essa manutenção das práticas alimentares, autores têm afırmado que a alimentação e as preferências alimentares estariam entre os últimos elementos a perderem sua conexão com a identidade nacional dos migrantes:

0 paladar, muitas vezes, é o último a se desnacionalizar, a perder a referência da cultura original. A culinária atua como um dos referenciais do sentimento de identidade; é por sua característica de "portable" [...] que ela pode se tornar referencial de identidade em terras estranhas (DUTRA, 1991, p. 17).

Para Calvo (1982), as práticas alimentares dos migrantes seriam as últimas a se transformarem por completo em caso de assimilação total. As práticas alimentares servem como uma proteção contra a aculturação e a perda da identidade cultural diante do contato com outros grupos (CONTRERAS; GRACIA, 2004, p. 218). Linger (2001) , em pesquisa realizada com brasileiros no Japão, afırma que, quando um(a) migrante procura bares e restaurantes brasileiros, ele(a) está saindo para comer e beber o Brasil - para participar de uma reafirmação consciente de sua identidade como brasileiro "deslocado".

5. Apesar dessas fortes relações entre comida e identidades nacionais, Mintz sugere que certas comidas utilizadas como marcadores étnicos, como macarrão, croissants, bagels, pizza, o croque monsieur, tornamse etnicamente neutralizadas, na medida em que são produzidas e consumidas dentro de um mercado global de alimentos. Nesse sentido, algumas comidas passam a ser étnicas, mas, posteriormente, com sua inserção global, também perdem este rótulo (MINTZ, 2001, p. 35). 
Essas afirmações sobre uma aparente fixidez da alimentação, no entanto, podem mascarar a ambiguidade das práticas alimentares. Ressaltando a resistência da alimentação às mudanças, o antropólogo Sidney Mintz (2001, p. 34) afırma que "seria mais fácil mudar o sistema político da Rússia do que fazê-los abandonar o pão preto; a China abandonaria sua versão do socialismo mais facilmente do que o arroz". No entanto, o autor surpreende-se ao observar que as populações desses dois países demonstram grande interesse em experimentar outras comidas, o que aponta para a posição ambígua das práticas alimentares. Mintz então conclui:

o fato de que tantas pessoas em sociedades outrora descritas como extremamente conservadoras estejam prontas a experimentar comidas radicalmente diferentes é uma evidência de que os comportamentos relativos à comida podem, às vezes simultaneamente, ser os mais flexíveis e os mais arraigados de todos os hábitos (p. 34).

Gupta (2006) analisa as culturas de especiarias e de cana-de-açúcar para argumentar que a arte culinária e os alimentos desempenham um papel decisivo na história da globalização. Seu trabalho é um bom exemplo das transformações das quais as práticas e representações alimentares são passíveis. 0 autor aponta para a dinamicidade da culinária e faz uma crítica aos estudos econômicos que acredito que pode ser estendida a outras áreas de estudo da alimentação:

Apesar da literatura sobre economia partir do princípio óbvio de que nada é mais difícil de mudar que as preferências dos povos pelas espécies de comida que mais lhe agradam (sendo, consequentemente, a procura de cer- tos tipos de alimentos relativamente inflexível), os fatos históricos demonstram a existência de uma extraordinária maleabilidade no tocante a gostos e tipos de consumo. Poucas áreas da vida social demonstram de modo tão preciso a hibridez dos encontros culturais como a preparação, a apresentação e o consumo de comida (GUPTA, 2006, p. 210).

A observação das práticas alimentares pode revelar, na sociedade global, as situações originais provocadas pelo contato de realidades socioculturais antes distanciadas. Calvo (1982) observa que, como uma dimensão dinâmica, esses contatos podem engendrar novas realidades socioculturais. Ao analisar as relações entre migração e alimentação, o autor sugere que o deslocamento de grupos sociais coloca em jogo três conjuntos de fatores: as características da sociedade de chegada, o contexto de origem do grupo e o plano de fundo econômico e político sobre o qual vão se estabelecer as relações. Calvo considera ainda que a alimentação dos migrantes pode ser compreendida como um continuum alimentar, formado por três estilos alimentares - dicotômico, dual e anômico - que correspondem ao estágio de adaptação dos migrantes ao novo contexto. Jerome (1980), por outro lado, entende as mudanças nas práticas alimentares como expressões da aprendizagem dos migrantes a um novo modo de vida e da aquisição de novos valores.

$\mathrm{Na}$ pesquisa realizada entre camaroneses em Paris, Lesdain (2002) encontrou migrantes com grande "curiosidade culinária”, que estariam dispostos a uma diversificação de suas práticas alimentares. Desse modo, a autora conclui que a manutenção das práticas alimentares do país de origem desses migrantes não corresponde a um desconhecimento nem a uma rejei- 
ção do consumo denominado francês, que faria parte das práticas cotidianas deles. De acordo com Lesdain, a manutenção da alimentação é utilizada como forma de inserção na França, servindo como modo de comunicação da cultura e dos valores dos migrantes aos "outros", além de ser uma alternativa econômica com a abertura de comércios "exóticos".

Uma perspectiva complexa das transformações e manutenções de práticas de imigrantes durante o processo migratório pode ser vista na edição de 2010 da revista eletrônica Anthropology of Food. Com o título Migrações, práticas alimentares e relações sociais: quando continuidade não é reprodução, e descontinuidade não é ruptura, a publicação mostra que continuidades e descontinuidades podem coexistir no estabelecimento dos migrantes ao novo contexto social.

Alguns autores sugerem entender as (des)continuidades como um processo de interpen

etração, tal como analisado por Roger Bastide (1956). Dessa forma, entendem que os imigrantes associam sua cultura de partida com a cultura do país onde vivem ao mesmo tempo em que adotam elementos dessa outra cultura, reproduzindo assim seu próprio significado de acordo com as lógicas de sua cultura, mas também com a estrutura social das sociedades de chegada (CRENN et al., 2010).

Em meu trabalho de campo com imigrantes brasileiros na Grande Boston, ouvi de meus interlocutores, na maioria das vezes, que eles se alimentavam de "comida brasileira" e que suas práticas alimentares não tinham sofrido mudanças significativas em relação às práticas alimentares que tinham no Brasil. Levando a sério a afirmação constante de que a "comida não tem gosto" e de que era possível "se acostumar" à comida de lá, propus-me pensar como o gosto poderia ajudar a compreender a experiência migratória de meus interlocutores. Para isso, retomei a literatura socio-antropológica sobre gosto a fim de propor duas perspectivas interpretativas para as afirmações dos imigrantes brasileiros.

\section{0 gosto na literatura socioantropológica}

0 que é gosto é uma questão complexa, que pode ser entendida de forma interdisciplinar, e se apresenta de modo multifacetado, contraditório e ambivalente (KORSMEYER, 2005). Como mostra Fischler (1992), o gosto passou a ser uma palavra polissêmica, compreendendo sentidos variados, como juízo estético, preferências (não apenas alimentares), afetividade, juízos de aceitação e recusa.

Segundo Chiva (1979), não se pode definir o gosto apenas como paladar, pois ele compreenderia mais do que a simples percepção de estímulos que os sabores dos alimentos (como doce, salgado, ácido e amargo) provocam na língua. Para o autor, a capacidade dessa percepção envolve o olfato, a temperatura, as texturas e o aparelho bucal. 0 autor também esclarece que a formação das capacidades gustativas dos indivíduos ocorre em um contexto social: quando bebês, os sujeitos recebem estímulos inseridos em um sistema de comunicação com um grupo social, que apresenta seus próprios valores. Também destacando a importância do contexto, Igor de Garine (1987) afirma que comida e sabor são adquiridos dentro de um recorte cultural, pois cada cultura e/ou subcultura apresenta um sistema de valores sobre alimentos e sabores.

Para Fischler (1995), o gosto é a sensação que reúne os aspectos palativos e olfativos 
do alimento desde que é ingerido na boca até o momento da sua deglutição. Um alimento é considerado de gosto melhor do que outro alimento quando inserido em um conjunto de referenciais construídos em relação ao que é um gosto bom e ao que é agradável. Esses gostos, na concepção do autor, são construídos desde a primeira infância, assim como apontado por Chiva (1979), e evoluem de acordo com as trajetórias e experiências dos indivíduos. Nesse processo, há, para Fischler, uma combinação de informações culturais e familiares que são interiorizadas pelos sujeitos a partir da vivência, aliadas a componentes biológicos dos indivíduos.

Essa definição de Fischler sobre o gosto é uma tentativa de unir, em uma só concepção, as dimensões biológicas e sociais do ato alimentar e dos processos de formação das práticas e preferências alimentares. Os estudos sobre alimentação na Antropologia e na Sociologia encontraram grande resistência no início da constituição dessas disciplinas por não se poder distinguir claramente se as práticas alimentares pertenciam ao domínio da natureza ou da cultura (POULAIN, 2004).

Segundo Csordas (1988), o conceito de gosto desenvolvido por Bourdieu (1979, 1983) - assim como sua noção de habitus - é parte de um projeto do autor de romper com a dualidade corpo e mente, apresentando-os de forma relacional. 0 gosto, para Bourdieu, está estreitamente relacionado ao conceito de habitus (que será retomado de forma mais consistente mais adiante no texto), e expressa uma cultura de classe que é introjetada no corpo dos indivíduos. 0 gosto, desse modo, é discriminante da classe e da hierarquia social ocupadas pelos indivíduos. Segundo Bourdieu (1979), o gosto alimentar depende, além de outros fatores, da ideia que cada classe social faz do corpo e dos efeitos dos alimentos sobre ele, além das categorias empregadas para avaliar seus efeitos, como força, saúde e beleza, entre outras. Nesse sentido, o corpo seria a objetivação de um gosto de classe. 0 gosto, nas palavras do autor, classifica o classificador (BOURDIEU, 1983). ${ }^{6}$

Essa concepção de gosto como expressão de classe social não depende apenas de critérios econômicos ou materialistas - a ocupação profissional também é importante. Já a classe social também não é definida apenas em padrões de renda financeira, mas como conjunto de práticas, predisposições e sentimentos. Para Bourdieu (1979), há uma distinção pelo gosto e, por essa razão, os gostos das classes dominantes são imitados pela classe média que aspira a ascensão social.

A distinção por meio do gosto já aparecia nos textos do político, cozinheiro e advogado francês Brillat-Savarin (1995 [1825]). Em Fisiologia do Gosto, escrito em 1825, o autor declara que o gosto relaciona-se aos prazeres, e que estes só podem ser experienciados por indivíduos que conhecem as regras das boas maneiras à mesa. De acordo com a perspectiva do escritor, a burguesia possuía a capacidade de desfrutar dos prazeres proporcionados pelos sabores dos alimentos por ser conhecedora da etiqueta.

Voltando às formulações de Bourdieu (1979), que elaborou a noção de gosto associada à distinção entre classes sociais, considero importante apontar as críticas

6. 0 historiador Flandrin, analisando o lugar do gosto nas relações sociais dos séculos XVII e XVIII, aponta também para a distinção entre a elite e as camadas subalternas a partir do modo de proceder à mesa (FLANDRIN, 1991). 
de Fischler a essa perspectiva teórica. Fischler (1992) lembra que as elaborações de Bourdieu não consideram as possibilidades de mudança sem que estejam associadas a uma mobilidade ou ascensão social, pois sua perspectiva está fundamentada sobre as noções de reprodução e transmissão. Além disso, ele pondera que Bourdieu adota a visão de que o convívio familiar e a educação constituem os principais fatores a partir dos quais os gostos familiares são transmitidos. Sem desconsiderar a importância desses fatores, Fischler observa que os gostos podem variar ao longo das diferentes fases da vida dos indivíduos, pois estão mais sujeitos a mudanças do que considerava Bourdieu.

Ambas as perspectivas - tanto a de Pierre Bourdieu quanto as críticas de Fischler - são importantes para pensar a questão do gosto - e da falta de gosto - apontada pelos brasileiros em Boston em minha pesquisa de campo. Mas é necessário ainda ir além, unindo a dimensão sensorial do gosto, e considerar a possibilidade, que aparece nos discursos de meus interlocutores, de "aprender a gostar" ou "acostumar-se ao gosto”. É nesse sentido que me proponho a pensar o gosto enquanto prática.

\subsection{Gosto como prática}

Para pensar o gosto enquanto prática, além de refletir sobre a obra de Bourdieu (1983) sobre as questões de habitus e estilo de vida é preciso voltar para os escritos de
Marcel Mauss. Com os conceitos fato social total e homem total, Mauss buscava os fatores que davam conta da totalidade - a saber, os elementos psicológicos, sociológicos e biológicos. No famoso ensaio As técnicas do corpo, Mauss procura pensar as maneiras pelas quais as pessoas se servem dos próprios corpos, e alerta que há técnicas para mergulhar, nadar, correr, e até mesmo para nossas atividades mais rotineiras, como dormir, comer e beber. Segundo Mauss, essas atividades seriam executadas de formas específicas por causa de um ensino técnico, uma aprendizagem. Cada sociedade - como franceses e ingleses, por exemplo - teria seus próprios hábitos, que seriam resultados de técnicas diferentes. A noção de habitus, ${ }^{7}$ tão cara à obra de Bourdieu, já se encontra nesse ensaio de Mauss (2003 [1935], p. 404):

Durante muitos anos tive a noção da natureza social do "habitus". Observem que digo em bom latim, compreendido na França, " $h a-$ bitus". A palavra exprime, infinitamente melhor que "hábito", a "exis" [hexis], o "adquirido" e a "faculdade" de Aristóteles (que era um psicólogo). Ela não designa os hábitos metafísicos, a "memória" misteriosa, tema de volumosas ou curtas e famosas teses. Estes "hábitos" variam não simplesmente com os indivíduos e suas imitações, variam sobretudo com as sociedades, as educações, as conveniências e as modas, os prestígios. É preciso ver técnicas e a obra da razão prática coletiva e individual, lá onde geralmente se vê apenas a alma e suas faculdades de repetição.

7. A noção de habitus aparece anteriormente na obra de São Tomás de Aquino a partir de leituras da obra de Aristóteles. Para o escolástico, habitus refere-se à natureza e à liberdade: "é uma disposição estável a agir facilmente, de modo feliz e portanto livre, para o bem ou para o mal, isto é, conformemente ou não aos fins de uma natureza". Ainda segundo Aquino, o habitus se desenvolve através da repetição, mas, diferentemente do hábito, isso ocorre "não por um automatismo adquirido, mas pelo aperfeiçoamento de uma inclinação natural com respeito à qual o sujeito permanece livre” (AQUINO apud NICOLAS, 2001, p. 84). 
Nesse pequeno trecho, além da noção de habitus, já aparecem outros temas recorrentes ao longo da teoria bourdiana da prática: hexis, imitação, prestígio e razão prática. ${ }^{8}$ As formas como as pessoas se utilizam dos corpos se desenvolvem por meio de processos de aprendizagem, e é a noção de prestígio "que faz o ato ordenado, autorizado, provado, em relação ao indivíduo imitador”. Estes atos são condicionados "pelos três elementos indissoluvelmente misturados" - a saber, o fisiológico, o sociológico e o psicológico. Estes processos de aprendizagem são iniciados na infância. Por essa razão, "talvez não exista 'maneira natural' no adulto" (MAUSS, 2003 [1935], p. 405).

Mauss considera a natureza instrumental do corpo: ele é, ao mesmo tempo, um objeto técnico e um meio técnico dos indivíduos. Já a técnica é um "ato tradicional eficaz”, pois as técnicas e sua transmissão dependem da tradição, e estão apoiadas em um sistema de símbolos morais e intelectuais, que definem atitudes que são permitidas ou não. Mauss evidencia que essas técnicas não são montadas apenas pelos indivíduos, mas pela sociedade da qual eles fazem parte, e pelo lugar que ocupam nela.

Apesar de curto, o ensaio As técnicas do corpo contempla as variações das técnicas entre os indivíduos ao longo das suas vidas. Mauss afirma que as técnicas variam de acordo com os sexos (hoje diríamos gênero), as idades, o rendimento e a forma de transmissão. Mauss chama atenção que a educa- ção possui um objetivo prático: o de adaptar o corpo a seu uso. As técnicas estão baseadas na noção de rendimento, o que ressalta a intencionalidade desse aprendizado.

É graças à sociedade que há uma intervenção da consciência. Não é graças à inconsciência que há uma intervenção da sociedade. É graças à sociedade que há segurança e presteza dos movimentos, domínio do consciente sobre a emoção e o inconsciente (MAUSS, 2003 [1935], p. 421).

Retomar a obra de Marcel Mauss é, portanto, estabelecer as origens de conceitos e pensamentos que deram origem a uma teoria da prática. Não encontramos em Mauss as distinções entre classes sociais exploradas no trabalho de Bourdieu, mas há uma relação entre habitus, prestígio, aprendizagem e diferenciação entre indivíduos, que pode variar ao longo das vidas destes, o que garante ao habitus uma relativa plasticidade. Quando os imigrantes em Boston dizem que "se acostumam" à comida local, eles estão enfatizando esses aspectos que, na obra de Mauss, estão relacionados. Mauss não utiliza o termo "gosto", que é desenvolvido por Bourdieu, mas desenvolve ideias a partir das quais ele pode ser pensado.

Gostaria de propor que o gosto seja pensado a partir de um conceito que alie tanto sua dimensão sensorial - a do paladar quanto o aspecto da prática. Entender o gosto enquanto prática significa entender, em

8. Assim como Bourdieu, Elias entende o habitus a partir da relação dinâmica entre classes sociais distintas. Como um "saber social incorporado", o habitus é entendido pelo autor tanto na dimensão individual quanto na social, que estão inter-relacionadas. Ao tentar se diferenciar das camadas sociais menos privilegiadas, as classes superiores desenvolveriam determinados padrões que, ao longo do tempo, serviriam como modelo para os indivíduos das demais classes sociais. A adoção desses novos padrões poderia também levar a mudanças profundas nas personalidades dos indivíduos, passando a constituir uma "segunda natureza” (ELIAS, 1990, 1993). 
poucas palavras, que não é o desejo que cria a prática, mas a prática que cria o desejo. As declarações abaixo feitas por dois interlocutores de minha pesquisa ${ }^{9}$ são representativas da relação entre prática e gosto:

Quando eu comi, pela primeira vez, as comidas daqui, eu não sentia o gosto de nada. $\mathrm{Pa}$ recia que estava comendo isopor. Mas depois que eu passei a comer, eu me acostumei... Levou um tempo. Hoje eu acho a comida daqui boa (informação verbal) ${ }^{10}$.

Eu cheguei aqui nos Estados Unidos, e uma prima minha me levou ao supermercado. Chegando lá, eu vi aquelas frutas bonitas, tudo bem organizado... Comprei banana, maçã... levei tudo pra casa. Mas, quando fui comer, não tinha gosto. A gente come porque precisa. E depois começa a se acostumar, e até acha bom (informação verbal) ${ }^{11}$.

A carne daqui não tem o mesmo gosto da carne no Brasil. É por isso que eles enchem a carne daqueles molhos prontos que se compra em supermercado. Antes eu detestava, achava doce. Hoje a minha boca se enche de água só de pensar... (informação verbal) ${ }^{12}$.

Para compreender as relações entre gosto e prática, utilizo as considerações para uma teoria da prática tal como desenvolvida por Alan Warde (2005). Para este autor, é o engajamento em práticas que explica o processo e a natureza do consumo. Warde defıne o conceito de prática a partir da defınição de Reckwitz:

Prática (práxis) no singular representa meramente um termo enfático para descrever o conjunto da ação humana (em contraste à teoria e ao mero pensamento). 'Práticas' no sentido da teoria das práticas sociais, no entanto, são algo a mais. Uma 'prática' (Praktik) é um tipo de comportamento rotinizado que consiste de diversos elementos interconectados uns aos outros: formas de atividades corporais, formas de atividades mentais, 'coisas' e seus usos, um conhecimento na forma de entendimento, saber-fazer (know -how), estados de emoção e conhecimento motivacional (RECKWITZ, 2002, p. 249, tradução nossa)

Warde apresenta ainda a noção de prática tal como definida por Schatzki, que contempla tanto a ideia de prática como entidade coordenada como a de prática como performance.

A primeira noção é de prática com um desdobramento temporal e nexus de dizeres e fazeres dispersos espacialmente. Exemplos são as práticas de cozinhar, votar, as práticas industriais, recreacionais e correcionais. Dizer que fazeres e dizeres formando uma prática constituem um nexus é dizer que estão ligados em certas maneiras. Os três maiores

9. Todos os nomes dos sujeitos da pesquisa foram substituídos por nomes fictícios para garantir sua privacidade

10. João, 32 anos, carpinteiro, vive há cinco anos na Grande Boston, em depoimento concedido à pesquisadora no ano de 2009.

11. Mariana, 26 anos, housecleaner, vive há três anos na Grande Boston, em depoimento concedido à pesquisadora no ano de 2009.

12. Cida, 35 anos, housecleaner, vive há sete anos na Grande Boston, em depoimento concedido à pesquisadora no ano de 2009. 
meios de ligação estão envolvidos: (1) por meio de entendimentos, por exemplo o que dizer e fazer; (2) por meio de regras explícitas que eu chamo de estruturas 'teleoafetivas' que abrangem finalidades, projetos, tarefas, objetivos, crenças, emoções e humores (SCHATZKI, 1996, p. 89, tradução nossa).

0 conceito de prática que considera os fazeres e dizeres contempla tanto as atividades práticas quanto as representações. Warde (2005) nota que prefere classificar os três elementos componentes que formam o nexus da prática como entendimentos, procedimentos e engajamentos.

Já o sentido da prática como performance refere-se à realização das práticas, à execução de dizeres e fazeres que atualizam e sustentam o sentido de nexus. Como aponta Warde (2005), a reprodução do nexus requer uma atuação constante e regular. Nesse sentido, as práticas são entidades coordenadas que requerem a performance para existirem. Os indivíduos, entendidos como agentes mentais e corporais, não apenas apresentam padrões de comportamentos corporais, como também modos rotinizados de entendimento, saber-fazer e desejo (RECKWITZ, 2002).

Com essas definições de Schatzki e Reckwitz, Warde (2005) pretende entender a prática como dinâmica, devido à sua lógica interna de operação, que implica tanto a reprodução quanto a inovação. Deste modo, abrange as adaptações, os improvisos e as experimentações realizadas pelos agentes sociais, e apresenta trajetória, história e desenvolvimento. 0 indivíduo, de acordo com o autor, é o ponto de intersecção de diversas práticas, e estas apresentam uma organização social que permite que os sujeitos tenham engajamentos sociais múltiplos, participando de redes sociais e locações diferenciais. As práticas podem ter conteúdo cultural arbitrário, mas são capazes de fornecer privilégios e vantagens. Esses entendimentos sobre as práticas enfatizam processos como hábitos, consciência prática, conhecimento tácito, tradição, entre outros. Warde esclarece que a performance em uma prática familiar não é completamente consciente nem totalmente reflexiva.

Pensar no gosto enquanto prática permite entender no contexto de minha pesquisa de campo que, apesar de não ter o mesmo gosto do Brasil, é possível "acostumar-se" à comida local ou "aprender a gostar" dela. Por meio da prática, com a repetição constante, ocorre a aprendizagem descrita por Mauss (2003 [1935]). Podemos aqui também pensar na obra contemporânea de Tim Ingold (2010) sobre o processo de construção do conhecimento. Em vez de ser transmitido entre gerações, o conhecimento, segundo o antropólogo britânico, seria resultado de habilidades, que são constituídas por meio da prática. ${ }^{13}$ Neste processo, Ingold ressalta o papel da experiência e do engajamento dos sujeitos no mundo.

Ressalto que o processo de aprendizagem também está relacionado à noção de prestígio, pois apreciar outras comidas implica níveis de acumulação de capital cultural que permitem maior inserção e circulação desses imigrantes na sociedade hospedeira. Aprender a gostar, neste senti-

13. Ingold explica que "na passagem das gerações humanas, a contribuição de cada uma para a cognoscibilidade da seguinte não se dá pela entrega de um corpo de informação desincorporada e contexto independente, mas pela criação, através de suas atividades, de contextos ambientais dentro dos quais as sucessoras desenvolvem suas próprias habilidades incorporadas de percepção e ação" (2010, p. 21). 
do, compreende uma estratégia na qual os imigrantes se engajam, pela prática, para viverem em um local longe do Brasil e para ajudá-los a lidar com a saudade em suas vidas diárias, como mostra o depoimento abaixo de uma interlocutora da pesquisa:

Se você não come a comida daqui, você só fica entre brasileiros, só fala português, e não faz mais nada, não aprende nada, não evolui, só fica pensando em voltar para o Brasil. Se você faz um esforço, tenta falar inglês, vai a um restaurante americano, vai no barbecue [churrasco], começa a apreciar a comida, você começa a ter uma outra vida... Nunca vai ser igual ao Brasil, vai dar saudade... Mas você tem uma vida... fica mais fácil... (informação verbal) ${ }^{14}$.

Para Wilk (2009), a vida diária seria muito difícil sem hábitos e rotinas - elementos essenciais em permitir que a vida diária proceda. A vida diária ocupa um espaço entre pensamento e hábito, apenas parcialmente consciente. Ainda assim, o autor aponta a dificuldade em adquirir um novo hábito.

Adquirir um novo hábito é como subir uma montanha no início, mas você espera que vai acabar chegando em algum lugar onde poderá relaxar e parar. É como um grande investimento no futuro. 0 trabalho duro que você está fazendo no presente é uma grande abstração, mas talvez uma vez que você o adquira ele pode tornar-se automático, e você não terá que pensar mais sobre isso. Seu corpo irá superá-lo, e sua mente poderá se mover para outras coisas (WILK, 2009, p. 148, tradução nossa).
Wilk divide a forma de adquirir uma nova forma de consumo na vida diária em duas partes: cultivação e naturalização. Cultivação refere-se aos processos que trazem para a consciência, a reflexão e o discurso os hábitos e as rotinas inconscientes. Para usar uma terminologia de Bourdieu, a cultivação leva os componentes do habitus para a dimensão da práxis. A cultivação pode ser passiva ou ativa, porque podemos ativamente iniciar novas rotinas, ou somos forçados a mudá-las. Conflitos entre rotinas podem levá-las adiante, pois temos que estabelecer prioridades.

Cultivação é parte essencial de qualquer forma de treinamento e educação, e é também um componente de muitas formas de competições e demonstrações públicas que levam ao olhar público formas habituais de consumo para exame e reflexão. Uma vida completamente cultivada seria impossível, pois seria inteiramente autoconsciente e reflexiva. A naturalização revela o processo que leva as práticas conscientes ao habitus, ou as impedem de serem conscientes. Muitos de nossos hábitos cotidianos são totalmente naturalizados e nós nunca pensamos neles, como quando ficamos com fome ou sede. Segundo Wilk, todos os dias temos a oportunidade de naturalizar algo novo.

$\mathrm{Na}$ vida diária, há uma luta em relação ao que deve entrar no repertório da rotina, e há regras de repetição que governam com que frequência coisas devem ser discutidas antes que possam ser feitas sem discussão, com que frequência devem ser repetidas por meio de acordo ou com supervisão antes que se tornem uma parte aceitável da rotina diária compartilhada (WILK, 2009, p. 151, tradução nossa).

14. Simone, 36 anos, housecleaner e professora de português, vive há seis anos na Grande Boston, em depoimento concedido à pesquisadora no ano de 2009 . 
Esse processo de naturalização também implica a possibilidade de aprender a gostar. Antonio está há dez anos nos Estados Unidos e, há cinco, ele, sua mulher e seus dois filhos têm Green Card. Ele vai ao Brasil pelo menos uma vez ao ano. Disse-me que atualmente, quando visita sua mãe em Minas Gerais e ela prepara o almoço, ele leva apenas "dois dias para se acostumar". Segundo ele, "é rápido". Contou-me que "está acostumado dos dois lados", o que lhe permite comparar comidas dos dois países. Hoje em dia, não tem dúvida de que a pizza do Brasil é melhor. Já o hamburger mais saboroso é o norte-americano, mas “o hambúrguer tradicional americano, não do McDonald's, o que é feito no restaurante com calma, que vai no grill, não na chapa”. Sobre os brasileiros que não concordam com ele, Antônio afirmou:

Não aprendeu a comer o hamburger daqui direito. É a pessoa que não se acostuma, que se acostumou a aquele hamburger do Brasil, com muita batata, excesso de milho... o daqui já não tem, já rejeita. E acha que aqui é tudo Mcdonalds, Burger King, não tiveram oportunidade de trabalhar em outra área e ficam preso em casa, de ir no restaurante e comer, ou de trabalhar no restaurante e ele mesmo fazer, ou pedir para alguém lá fazer daquele modo tradicional, que hoje eu não tenho dúvida que é melhor do que o do Brasil (informação verbal) ${ }^{15}$.
A declaração de Antônio aponta que os imigrantes que não "aprendem a comer" a comida norte-americana têm menores possibilidades de inserção e de circulação nos Estados Unidos, inclusive de trabalho.

\subsection{A interação pelo gosto}

Assim como "aprender a gostar" ou "acostumar-se" pode ser entendido enquanto prática, o que é parte das estratégias de imigrantes para viverem em um novo contexto social, a formação ou manutenção do gosto também pode ser entendida em sua importância na relação entre pessoas. Isso pode ser percebido em diferentes situações em que vivenciei trocas alimentares durante o trabalho de campo. Presentear um colega ou amigo com chocolate enviado por parentes do Brasil, ou ainda partilhar um bolo de aipim preparado "como no Brasil" são exemplos de como a comida pode ser utilizada para criar laços ou estreitar relações entre os imigrantes. De forma semelhante, quando começam a apreciar a "comida americana”, os brasileiros passam a frequentar, com maior facilidade, momentos de confraternização organizados por norte-americanos, como o jantar do dia de Ação de Graças (Thanksgiving), tradicional data comemorativa nos Estados Unidos ${ }^{16}$. Pelo menos duas interlocutoras contaram que não compareceram ao jantar realizado pelos patrões norte-americanos, apesar da insistência deles,

15. Depoimento de Antonio, que mora há dez anos nos Estados Unidos, em depoimento concedido à pesquisadora no ano de 2009.

16. 0 Thanksgiving, Dia de Ação de Graças, é celebrado na quarta quinta-feira do mês de novembro. A origem desse feriado é bastante controversa. Historiadores acreditam que teria sido iniciado no século XVII por líderes colonialistas para celebrar uma boa colheita. Um dos mitos de origem da celebração conta que peregrinos na colônia de Plymouth, em New England, nordeste dos Estados Unidos, não tinham comida suficiente para se alimentar, e foram alimentados por índios norte-americanos (os Native-Americans), que lhes ensinaram a pescar e lhes deram sementes. 
por não apreciarem o gosto do peru, principal prato servido nessa data. Uma delas, que trabalha como housecleaner, reconheceu que sua participação seria importante para estabelecer uma relação de maior intimidade com os patrões: "quando a gente recusa um convite desses, perde a chance de fazer conhecer melhor a família, e até de fazer amizade" (informação verbal) ${ }^{17}$.

Pensar no gosto enquanto interação vai ao encontro de propostas elaboradas por antropólogos como Paul Stoller (1989), que podem ser considerados expoentes da Antropologia dos Sentidos. Stoller critica a antropologia ao propor que a percepção dos sentidos seja incorporada a toda descrição social e prática etnográfica. 0 autor retoma a obra $A$ crítica do julgamento, publicada originariamente em 1790, na qual o filósofo Emmanuel Kant hierarquiza os sentidos, relegando o gosto, o cheiro e o toque ao estatuto de brutos, em oposição ao sentido estético. De acordo com Stoller, a influência de Kant aliada ao intelectualismo visual dos pensadores do Iluminismo resultou em uma desvalorização dos sentidos nos discursos dos intelectuais, retirando, deste modo, os aspectos sensoriais das experiências dos observadores ocidentais.

Ainda segundo Stoller (1996), baseada na noção de textualismo de Geertz, o foco da evocação e análise antropológica tem sido excessivamente visual. Os antropólogos seguidores deste modelo teórico tornaram-se leitores densos de textos culturais que eles analisavam do mesmo modo que a crítica literária analisa uma novela ou um poema. Stoller alerta para o fato de que transformar a experiência cultural em textos limita a análise cultural ao sentido da visão, o que pode nos afastar do mundo sensorial do gosto, da audição e do tato. Segundo o autor, povos em algumas sociedades veem o mundo primeiramente em termos visuais, mas em outras sua percepção do mundo pode ocorrer primeiramente por meio de outros sentidos.

A particularidade da Antropologia dos Sentidos está não apenas na importância dos sentidos para a compreensão da interação social, pois envolve uma abordagem epistemológica (HOWES, 2003). A percepção sensorial não é entendida somente como um ato biológico, mas entendida em suas dimensões sociais e culturais (CLASSEN, 1997). Os sentidos, de acordo com esta visão teórica, vão além das cinco categorias popularmente conhecidas no Ocidente - visão, olfato, tato, paladar e audição -, podendo incluir outras categorias, como emoções e sentimentos. Além disso, a percepção sensorial é considerada dinâmica e variável tanto em uma única cultura como entre grupos culturais. Em geral, a investigação antropológica sobre os sentidos se estende para além das observações das sensações preliminares, compreendendo o significado que emerge de tais experiências sensoriais (HOWES, 2003).

A Antropologia dos Sentidos propõe um olhar diferenciado (ou talvez ampliado) sobre pontos de vista relevantes para outras áreas da Antropologia. Howes nos apresenta um exemplo: enquanto a Antropologia da Alimentação enfatiza aspectos políticos, econômicos e/ou simbólicos das práticas e saberes alimentares, a Antropologia dos Sentidos se concentra nos aspectos sensoriais da comida e da refeição. Deste modo, textura e gosto, por exemplo, podem de 2009. 
ser percebidos em relação à interação social entre indivíduos. Como sugere Stoller (1996), os antropólogos devem ajustar suas antenas perceptuais e voltar aos sentidos para compreender as sociedades e as culturas, o que pode levá-los a descobrir outras formas como grupos culturais percebem o mundo à sua volta a partir de sons, cheiros, gostos e texturas.

A importância dos sentidos e da percepção sensorial para a vida das pessoas e seu papel nas interações entre elas já tinha sido explorada por Simmel, em texto escrito originariamente em 1912. Em Ensaio sobre a Sociologia dos Sentidos, o autor alemão hierarquiza os sentidos de acordo com seu grau de relevância, de forma semelhante à de Kant, criticada por Stoller (1989), a saber: em primeiro, a visão, seguida pela audição, e em terceiro, o olfato, o mais inferior. Simmel, no entanto, aponta para as características peculiares e reconhece os valores sociológicos de cada um desses sentidos, como o de ser um instrumento de reconhecimento, o de possuir valor sentimental, a capacidade de constituir a memória e a subjetividade, além do caráter cognitivo (SIMMEL, [1912] 1981). Curiosamente, Simmel não cita o paladar, embora as particularidades apontadas pelo autor de forma diferenciada para cada um dos sentidos possam também ser apontadas para a percepção do gosto.

Uma crítica pertinente à Antropologia dos Sentidos é realizada por Tim Ingold. 0 antropólogo, baseando-se na fenomenologia de Merleau-Ponty e na psicologia de James Gibson, contraria o relativismo, segundo o qual as experiências recebidas pelo corpo são modeladas por cada cultura, que lhes oferece sentido. Ingold (2008, p. 2) afırma que a percepção parte de um "engajamento ativo e exploratório da pessoa inteira, corpo e mente indissolúveis, num ambiente ricamente estruturado". Ainda de acordo com o antropólogo britânico, as formas como as pessoas percebem o mundo diferem devido à base existencial do mundo em que habitam. As críticas de Ingold não citam diretamente o paladar, pois estão centradas em recusar a ideia de um "imperialismo visual”, mas concluem que qualquer modalidade sensorial deve estar aliada à atividade prática, à experiência corporal e vivida. Desse modo, percebemos que os sentidos, de forma geral, e o paladar, que é o foco deste artigo, não devem ser dissociados de nosso engajamento no mundo, o que inclui nossas relações sociais.

A importância do gosto na interação social pode ser percebida em meu trabalho de campo na forma como os imigrantes valorizam o "gosto do Brasil", que é sempre considerado melhor e inigualável ${ }^{18}$. Ainda que possam "aprender a gostar" de uma nova comida e "acostumar-se" a ela, esta não chega a superar ou substituir o sabor da "comida brasileira”. A comida brasileira, para os imigrantes, está relacionada às dimensões afetivas do ambiente doméstico e familiar. A comida é, portanto, uma manifestação das relações mais próximas que os imigrantes procuram manter no Brasil. 0 gosto, por sua vez, está também relacionado a essas interações sociais.

Como aponta a antropóloga inglesa Diana Mata Codesal a respeito de equatorianos na cidade espanhola Santander, os migran-

18. A importância dada ao "gosto do Brasil" também pode ser percebida nas propagandas dos restaurantes brasileiros na Grande Boston, que muitas vezes utilizam essa expressão como forma de divulgação de seus estabelecimentos. 
tes estão tentado se manter sensorialmente conectados com seu passado em seu país de origem comendo comidas conhecidas como uma experiência corpórea de continuidade. Dessa forma, a comida fornece um sentido por meio do qual o lar original e a nova casa estão ligados. Ativando as memórias do corpo pode-se fornecer conforto psicológico e emocional em um contexto de drásticas mudanças causadas pela migração (CODESAL, 2010).

Se "aprender a gostar" pode ser assimilado por meio da prática, as preferências alimentares podem ser transmitidas. Desse modo, é possível compreender a importância de os imigrantes alimentares seus filhos, principalmente os nascidos nos Estados Unidos, com "comida brasileira”. A partir dela e de outros elementos, como a língua, é possível estabelecer relacionamento dessas crianças com o local de origem de seus pais e com os parentes que permanecem no Brasil. Dessa maneira, os sentidos que têm relação com a comida, sejam eles cheiros ou gostos, são parte da socialização.

A comida apresenta uma dimensão comunicativa. A comida é comparada por diversos autores com o sistema linguístico que, por meio de símbolos, que são combinados e classificados, comunica uma estrutura social subjacente (LÉVI-STRAUSS, 1965; DOUGLAS, 1971; BARTHES, 1961). No caso dos imigrantes com quem convivi, essa linguagem comum criada por meio da comida, aliada a seus aspectos sensoriais, ajuda a estabelecer e fortalecer vínculos à distância. Lucas contou-me não ter tido dificuldades com seus filhos, de oito e dez anos, nascidos nos Estados Unidos. Quando eles não queriam comer algo, os pais insistiam, para que eles "aprendessem a comer”. Lucas afırma que hoje eles são "como brasileiros", pois não podem ficar dois dias sem comer arroz e feijão. Nas palavras dele, os filhos se "culturaram" a partir dos pais, o que é importante, principalmente, quando as crianças retornam ao Brasil, nas férias, para não "estranharem" a comida preparada pelas avós.

\section{Considerações Finais}

Para além de suas dimensões políticas, econômicas e socioculturais, a migração mostra-se um contexto interessante para problematizar a continuidade de hábitos e costumes considerados resistentes a mudanças, como a alimentação. Tida como participante da construção de identidades, a comida apresenta-se como importante elemento que distingue indivíduos e grupos sociais. Em minha pesquisa de campo, observei também que a comida é parte das estratégias que os sujeitos utilizam para lidar com a distância do país de origem e de seus laços afetivos, pois ajuda a recriar o ambiente doméstico e familiar que mantinham no Brasil. Desse modo, destaco aqui que, além de pensarmos no que se come, é importante também atentarmos para a sensorialidade da comida. Assim podemos entender o contexto no qual a comida não tem gosto e a possibilidade de "aprender a gostar" dessa comida ou "acostumar-se" a ela.

\section{Referências}

BARBOSA, L. Feijão com arroz e arroz com feijão: o Brasil no prato dos brasileiros. Horizontes Antropológicos, ano 13, n. 28, p. 87-116, jul./dez. 2007.

BARTHES, R. Pour une psycho-sociologie de l'alimentation contemporaine. Cahiers des Annales, n. 28, p. 977-986, 1961. 
BASTIDE R. La causalité externe et la causalité interne dans l'explication sociologique. Cahiers internationaux de sociologie, n. 21, p. 77-99, 1956.

BOURDIEU, P. La Distinction: critique sociale du jugement. Paris: Editions de Minuit, 1979.

Gostos de classe e estilos de vida. In: ORTIZ, R. (Org.). Bourdieu. Ática, São Paulo, Coleção Grandes Cientistas Sociais, n. 39, 1983.

BOYD, M. Family and personal networks in international migration: recent developments and new agenda. International Migration Review, v. 23, n. 3, p. 638-670, outono 1989.

BRILLAT-SAVARIN. A fisiologia do gosto. São Paulo: Companhia das Letras, [1825] 1995.

CALVO, M. Migration et Alimentation. Social Science Information, v. 21, n. 3, p. 383-446, 1982.

CAVIGNAC, J. A.; OLIVEIRA, L. A. História e etnografia nativas da alimentação no Brasil: notas biográficas a respeito de um antropólogo provinciano. Imburana - revista do Núcleo Câmara Cascudo de Estudos Norte-Rio-Grandenses/UFRN. n. 2, nov. 2010.

CHIVA, M. Comment la personne se construit enmangeant. Communication, n.31, 1979.

CLASSEN, C. Foundations for an Anthropology of the Senses. International Social Science Journal. n. 153, p. 401-412, 1997.

CODESAL, D. M. Eating abroad, remembering (at) home. Anthropology of food [Online], n.7. December, 2010. Disponível em: <http://aof.revues. org/index6642.html>. Acesso em: 21 jul. 2011.

CONTRERAS H. J.; GRACIA A. M. Alimentación y cultura: perspectivas antropológicas. Barcelona: Ariel, 2004.

CRENN, C.; HASSOUN, J.P., MEDINA, F. X. Introduction: Repenser et réimaginer l'acte alimentaire en situations de migration. Anthropology of food[Online], n. 7, December,. 2010. Disponivel em: $<$ http://aof.revues.org/index6672.html $>$. Acesso em: 8 jun. 2010.
CSORDAS, T. J. Embodiment as a paradigm for anthropology. Ethos. n. 18, p. 5 - 47, 1988.

DOUGLAS, M. Deciphering a Meal. In: GEERTZ, C. (Org.). Myth, Symbol and Culture. Nova York: Norton, 1971. p. 61-81.

DUTRA, R. C. de A. Cozinha e identidade nacional: notas sobre a culinária na formação da cultura brasileira segundo Gilberto Freyre e Luís da Câmara Cascudo. Anais do Seminário Gastronomia em Gilberto Freyre, 2005.

. A boa mesa mineira. 1991. 192f. Dissertação (Mestrado em Antropologia Social). UFRJ, Museu Nacional: Rio de Janeiro, 1991.

ELIAS, N. O Processo Civilizador: Uma História dos Costumes. vol. 1. Rio de Janeiro: Jorge Zahar, 1990.

ELIAS, N. O Processo Civilizador: Formação do Estado e Civilização. vol. 2. Rio de Janeiro: Jorge Zahar, 1993.

FISCHLER, C. Gastro-nomía y gastro-anomia. Sabiduría del cuerpo y crisis biocultural de la alimentación contemporánea. In: CONTRERAS, J. (Org.). Alimentación y Cultura: necesidades, gustos y costumbres. Barcelona: Universitat de Barcelona, 1995.

. L'Homnivore. Paris: Odile Jacob, 1992.

FLANDRIN, J. L. A distinção pelo gosto. In: ARIES, P.; CHARTIER, R. História da vida privada: da Renascença ao Século das Luzes. São Paulo: Cia. das Letras, 1991.

FRY, P. Feijoada e soul food 25 anos depois. In: ESTERCI, N., FRY, P., GOLDENBERG, M. (Orgs). Fazendo Antropologia no Brasil. Rio de Janeiro: DPCA, 2001.

. Feijoada e Soul Food: Notas sobre a Manipulação de Símbolos Étnicos e Nacionais. In: . Para inglês ver: identidade e política na cultura brasileira. Rio de Janeiro: Zahar, 1982.

GANS, H. The Urban Villagers: Group and Class in the Life of Italian-Americans. New York, Basic Books: 1962. 
GARINE, I. de. Alimentação, culturas e sociedades. 0 Correio da Unesco. Rio de Janeiro, v. 15, n. 7, 1987.

GEERTZ, C. Do ponto de vista dos nativos: a natureza do entendimento antropológico. In: 0 Saber Local: novos ensaios de Antropologia Interpretativa. Petrópolis: Vozes, 2002. p. 85-107.

A interpretação das culturas. Rio de Janeiro: Zahar, 1978.

GONÇALVES, J. R. S.. A fome e o paladar: a antropologia nativa de Luís da Câmara Cascudo. Estudos Históricos, n. 33, 2004.

GUPTA, A. Movimentações globais das colheitas desde a 'Era das Descobertas' e transformações das culturas gastronômicas. In: SANCHES, M. R. Portugal não é um país pequeno: contar o "império" na pós-colonialidade. Lisboa: Cotovia, p. 193-213, 2006.

HOWES, D. Sensual Relations: Engaging the Senses in Culture and Social Theory. Ann Arbor: University of Michigan Press, 2003.

INGOLD, T. Da transmissão de representações à educação da atenção. Educação, Porto Alegre, v. 33, n. 1, p. 6-25, jan./abr. 2010.

INGOLD, T. Pare, olhe, escute! Visão, audição e movimento humano. Ponto Urbe [Online], n. 3, 2008. Disponivel em: <http://pontourbe.revues. org/1925>. Acesso em: 7 ago. 2015.

JACKSON, M. Knowledge of the Body. Man, n. 18, p. 327-345, 1983.

JEROME, N. W. Diet and acculturation (the case of black American immigrants). In: JEROME, N. W., KANDEL, R. F., PELTO, G. H. (Ed.). Nutritional Anthropology: Contemporary Approaches to Diet and Culture. Pleasantville, New York: Redgrave Publishing, p. 275-326, 1980.

KORSMEYER, C. (Ed.). The Taste Culture Reader: Experiencing Food and Drink. Oxford and New York: Berg, 2005.

LESDAIN, S. B. de. Alimentation et migration, une définition spatiale. In: GARABUAU-MOUSSAOUI,
I.; PALOMARE, E.; DESJEUX, D. (Ed.). Alimentations contemporaines. Paris: L'Harmattan, p. 173189, 2002 .

LÉVI-STRAUSS, C. Le triangle culinaire. L'Arc, n. 26, p. 19-29, 1965.

LIMA, A. Brasileiros na América. Boston: 2009.

LINGER, D. T. No One Home: Brazilian Selves Remade in Japan. Stanford: Stanford University Press, 2001.

MACIEL, M. E. Identidade cultural e alimentação. In: CANESQUI, A. M.; GARCIA, R. W. D. Antropologia e nutrição: um diálogo possível. Rio de Janeiro: Fiocruz, p. 23-47, 2005.

MARCUS, A. (Re)creating places and spaces in two countries: Brazilian transnational migration processes. Journal of Cultural Geography, v. 26, n. 2, p. 173-198, 2009.

MARGOLIS, M. L. Invisible minority: Brazilians in New York City. Massachusetts: Allyn and Bacon, 1998.

MASSEY, D. The social organization of migration. In: MASSEY, D.; ALARCON, R.; DURAND, J.; GONZÁLEZ, H. Return to Aztlan: the social process of international migration from Western Mexico. Berkeley: University of California Press, p. 139-171, 1990.

MAUSS, M. As técnicas do corpo. In: Sociologia e Antropologia. São Paulo: Cosac \& Naify, [1935], p. 399-424, 2003.

MENDONÇA, R. U. Analysis of Markets in the United States for Brazilian Fresh Produce Grown in Massachusetts. Graduate School of the University of Massachusetts Amherst. Master of Sciences, 2007.

MINTZ, S. W. Food and anthropology: a brief overview. Rev. bras. Ci. Soc., v. 16, n. 47, 2001. Disponivel em: <http://www.scielo.br/scielo.php?script=sci_arttextCtpid=S010269 092001000300002 ctln$\mathrm{g}=$ enctnrm=iso $>$. Acesso em: 23 maio 2014.

NICOLAS, M. J. Vocabulário da Suma Teológica. In: AQUINO, S. T. Suma Teológica I. São Paulo: Edições Loyola, p. 71-102, 2001. 
PENFOLD, S. The Donut: A Canadian History. Toronto: University of Toronto Press, 2008.

PILCHER, J. Que vivan los tamales! Albuquerque: University of New Mexico Press, 1998.

POULAIN, J.P. Sociologias da Alimentação: Os comedores e o espaço social alimentar. Florianópolis: Editora da UFSC, 2004.

RECKWITZ, A. Toward a Theory of Social Practices: A Development in Culturalist Theorizing. European Journal of Social Theory, v. 5, n. 2, p. 243-263, 2002.

REIS, L. V. S. A aquarela do Brasil: a mestiçagem e a construção nacional do samba e da capoeira. São Paulo: Mimeo, 1994.

SAYAD, A. A imigração ou os paradoxos da alteridade. São Paulo: EDUSP, 1998.

SCHWARCZ, L. M. Complexo de Zé Carioca: notas sobre uma identidade mestiça e malandra. Revista Brasileira de Ciências Sociais, n. 29, 1995.

SCHATZKI, T. Social Practices: A Wittgensteinian Approach to Human Activity and the Social. Cambridge: Cambridge University Press, 1996.

SIMMEL, G. Essai sur la sociologie des sens. In: . Sociologie et Épistémologie. Paris: PUF, [1912], p. 223-238, 1981.

STOLLER, P. Sounds and Things: Pulsations of Power en Songhay. In: LADERMAN, C.; ROSEMAN, M. (Orgs.). The perfomance of healing. New York: Routledge, p. 165-184, 1996.

The Taste of Ethnographic Things: The Senses in Anthropology. Philadelphia: University of Pennsylvania Press, 1989.

WARDE, A. Consumption and Theory of Practice. Journal of Consumer Culture, v. 5, n. 2, p. 131153, 2005.

WILK, R. The Edge of Agency: Routines, Habits and Volition. In: SHOVE, E., TRENTMANN, F., WILK, R. (Ed.). Time, Consumption and Everyday Life: Practice, Materiality and Culture. Oxford: Berg, p. 143-156, 2009. 
RESUMO

Este artigo baseia-se em dados de uma pesquisa etnográfica sobre as práticas alimentares de imigrantes brasileiros na Grande Boston, e discute as afirmações recorrentes dos sujeitos de pesquisa de que a comida nos Estados Unidos "não tem gosto", mas que é possível "se acostumar" a ela. Nesse sentido, discute o que é gosto, a partir da literatura socioantropológica, e propõe duas abordagens interpretativas: o gosto é entendido (1) enquanto prática, contemplando a dinamicidade das ações dos interlocutores em seu cotidiano, e (2) como elemento constituinte das interações sociais dos sujeitos da pesquisa. Dessa forma, o artigo conclui que o gosto, em sua dimensão sensorial, é parte das estratégias que os sujeitos utilizam para viver no contexto migratório, lidar com as dificuldades nos Estados Unidos e manter laços com familiares, parentes e amigos que permaneceram no Brasil.

\section{PALAVRAS-CHAVE}

Gosto. Comida. Alimentação. Migração internacional. Brasileiros nos Estados Unidos.

\section{ABSTRACT}

This article is based on data from an ethnographic research on the eating habits of Brazilian immigrants in Greater Boston, and discusses the recurrent statements of the research subjects that the food in the United States "has no taste", but that it is possible "to get used to" this food. In this sense, it discusses what taste is, from the anthropological literature, and proposes two interpretive approaches: the taste is understood (1) as practice, observing the dynamics of the immigrants' actions in their daily lives, and (2) as element engaged in the social interactions of the research subjects. Thus, the article concludes that the taste, in its sensory dimension, is part of the strategies that individuals use to live in the migratory context, in order to deal with the difficulties in the US and maintain ties with family, relatives and friends who remained in Brazil.

\section{KEYWORDS}

Taste. Food. Foodways. International migration. Brazilians in the United States. 